\title{
Sistem Informasi Multiplatform Repositori Data Dosen Berbasis React Menggunakan Framework Kanban
}

\author{
Habibie Ed Dien ${ }^{1}$, Putra Prima Arhandi ${ }^{2}$, Aditya Eka Pradana P. ${ }^{3}$, Deby Silvia A. ${ }^{4}$ \\ Manajemen Informatika, Jurusan Teknologi Informasi, Politeknik Negeri Malang \\ e-mail: ${ }^{1}$ habibie@polinema.ac.id
}

Diterima: 25 Maret 2021; Direvisi: 09 Mei 2021; Disetujui: 17 Mei 2021

\begin{abstract}
Abstrak
Dosen adalah seorang pendidik profesional yang mengemban tugas tridharma perguruan tinggi. Luaran setiap dosen dari tridharma adalah pendidikan dan pengajaran, penelitian, dan pengabdian. Luaran tersebut memiliki data atau dokumen yang penting dan sangat banyak yang mendukung jenjang karirnya. Oleh karena itu, perlu dilakukan pengembangan sistem informasi untuk memanajemen data tersebut. Salah satu solusinya adalah dengan membangun sistem informasi repositori untuk mengelola data-data dosen. Data itu meliputi biodata, kepangkatan, pendidikan, penelitian, pengajaran, pengabdian, sertifkasi, dan pelatihan. Metode pengembangan sistem dibangun dengan framework Kanban. Hasil penelitian ini berupa aplikasi android menggunakan React Native dan web yang dibangun dengan ReactJS menggunakan bahasa pemrograman TypeScript. Fitur yang telah dibangun terdiri dari notifikasi, web service API, manajemen akun, dan manajemen dokumen digital. Fitur web service API berfungsi untuk pertukaran data antar platform, sedangkan notifikasi membantu admin untuk mengetahui informasi jika terdapat pembaruan dokumen digital dari dosen atau sebaliknya. Manajemen akun dan dokumen digital membantu untuk mengelola data tridharma. Jenis pengguna aplikasi terdiri dari administrator dan dosen. Pengujian fungsional dilakukan dengan metode blackbox pada berbagai perangkat dengan hasil pengujian sesuai harapan dan dapat beroperasi dengan baik. Selain itu, pengujian telah dilakukan dengan positif tes dan negatif tes, artinya sistem dapat merespon dengan baik terhadap data yang valid maupun yang tidak valid.
\end{abstract}

Kata kunci: repositori, dosen, multiplatform, react, web, android

\begin{abstract}
Lecturer is a professional educator who carries out the task of the tridharma college. The output of each lecturer from the tridharma is education and teaching, research, and dedication. The output has very many important data or documents that support his career path. Therefore, it is necessary to develop an information system to manage the data. One solution is to build a repository information system to manage lecturer's data. The data includes biodata, career, education, research, teaching, dedication, certification, and training. The system development method is built with the Kanban framework. The results of this study are an android application using React Native and a web built with ReactJS using the TypeScript programming language. The features that have been built consist of notification, a web service API, account management, and digital document management. The web service API feature functions to exchange data between platforms, while notifications help admins find information if there is an update to a digital document from a lecturer or vice versa. Account management and digital documents help to manage tridharma data. Types of application users consist of administrators and lecturers. Functional testing is carried out by the blackbox method on various devices with test results as expected and can operate properly. In addition, testing has been carried out with positive tests and negative tests, meaning that the system can respond well to valid and invalid data.
\end{abstract}


Keywords: repository, lecturer, multiplatform, react, web, android

\section{PENDAHULUAN}

Menurut KBBI repositori adalah tempat penyimpanan sesuatu [1]. Repositori bermanfaat bagi organisasi terutama perguruan tinggi dalam mengelola data dan informasi instansi. Data dosen adalah salah satu unsur penting dalam aktivitas perguruan tinggi, baik itu berupa dokumen fisik maupun dokumen digital. Adanya sistem repositori juga sangat mendukung dalam penilaian akreditasi institusi. Berdasarkan 9 (sembilan) kriteria yang ditetapkan oleh BAN-PT [2], tata kelola dan sumber daya manusia (SDM) adalah elemen penilaian terpenting terhadap kapasitas institusi dan keefektifan pendidikan. Indikator penilaian terpenting adalah tersedianya dokumen formal dan bukti yang sahih terkait upaya institusi melindungi integritas akademik dan kualitas pendidikan tinggi. Hal itu dapat terwujud dengan dibangunnya sistem informasi repositori untuk mengelola data SDM, sehingga dapat diketahui kapasitasnya baik dari segi rasio, jumlah, ratarata, kecukupan, dan kualifikasi.

Teknologi sistem informasi makin berkembang pesat dengan munculnya berbagai piranti seperti gawai, jam pintar (smartwatch), tablet, dan sebagainya. Sehingga kebutuhan akan dukungan sistem untuk berbagai platform (multiplatform) juga perlu dipertimbangkan agar dapat membantu aktivitas manusia sehari-hari. Application Programming Interface (API) merupakan solusi terkini yang mendukung untuk komunikasi antar platform. Jika sebuah sistem telah tersedia fitur web service API, maka ia akan mudah untuk bertukar data dengan aplikasi-aplikasi dari piranti bergerak melalui jaringan internet. Selain itu, fitur API juga berpeluang besar untuk dapat dintegrasikan dengan sistem yang sudah ada di suatu instansi.

React adalah pustaka JavaScript untuk membangun user interfaces (UI) yang terkenal dengan dukungannya untuk membangun sistem multiplatform [3]. Jargonnya yang cukup terkenal adalah "Learn once, write anywhere" artinya "belajar sekali, menulis di mana pun". Pustaka yang dikembangkan oleh Facebook ini cukup terkenal di kalangan pengembang perangkat lunak frontend [4], [5]. React native [6] adalah kerangka aplikasi seluler berlisensi open source yang digunakan untuk mengembangkan aplikasi Android, Android TV, iOS, macOS, tvOS, web, windows, dan UWP yang memungkinkan dikombinasi dengan kerangka kerja React.

Beberapa penelitian terkait sistem repositori data dosen [7]-[11] mayoritas dibangun menggunakan bahasa pemrograman PHP dengan basis data MySQL. Sistem yang dibangun hanya mendukung platform web. Beberapa fitur fungsional sudah cukup untuk mengolah data tridharma, baik untuk kebutuhan kenaikan pangkat, analisis beban kerja, dan sistem pelaporan. Ada juga sistem yang telah mendukung fitur responsive [8], sehingga UI stabil ketika diakses melalui perangkat gawai maupun desktop. Fitur responsive memang cukup menjanjikan untuk pengguna gawai, namun kurang interaktif ketika ada notifikasi yang ingin disampaikan ke pengguna tertentu. Notifikasi sangat berguna terutama dosen yang memiliki kesibukan sangat padat, sehingga ketika ada data atau dokumen yang kurang lengkap, sistem akan terus memberi info untuk segera melengkapinya.

Penelitian ini mencoba menyelesaikan permasalahan tersebut dengan teknologi informasi terbaru yaitu React. Solusi terkini yang mendukung sistem multiplatform dengan komunikasi menggunakan web service API. Lokasi penelitian di Jurusan Teknologi Informasi (JTI), Politeknik Negeri Malang (Polinema) dengan obyek penelitian sebuah sistem informasi multiplatform repositori untuk mengolah data tridharma dosen. Fitur notifikasi menjadi nilai tambah untuk menginformasikan pembaruan yang terjadi di sistem, baik itu perubahan data atau dokumen, bahkan pemenuhan syarat-syarat dokumen digital yang perlu dilengkapi oleh dosen.

\section{METODE PENELITIAN}


Penelitian ini dilakukan dengan beberapa tahapan dan metode. Tahapan dan metode yang dimaksud adalah sebagai berikut.

\subsection{Studi Literatur dan Wawancara}

Pada tahap ini peneliti melakukan proses literasi untuk memperoleh data dan informasi yang mendukung dengan penelitian ini. Salah satunya adalah menelaah penelitian terdahulu. Hal itu dilakukan agar terlihat perbedaan atau kebaruan dalam penelitian ini dibanding dengan penelitian sebelumnya.

Wawancara dilakukan dengan admin JTI Polinema. Hal ini dilakukan untuk memperoleh data dan informasi yang dibutuhkan untuk menganalisis kebutuhan pengguna, merancang, dan membangun sistem sesuai tujuan dan harapan yang ingin dicapai.

\subsection{Identifikasi dan Analisis Masalah}

Berdasarkan hasil wawancara dengan admin JTI, terindentifikasi beberapa permasalahan yang perlu dicarikan solusi. Diantaranya adalah sebagai berikut:

1. Dokumen digital maupun konvensional masih tersimpan pada perangkat masing-masing dosen;

2. Penyimpanan dokumen-dokumen penting terkait data dosen belum terstruktur;

3. Perlunya dukungan sistem multiplatform untuk mengolah dokumen atau data dosen, sehingga dapat diakses dari berbagai perangkat.

\subsection{Analisis Kebutuhan dan Perancangan Sistem}

Metode pengembangan perangkat lunak yang digunakan adalah agile dengan framework Kanban [12]. Pada metode ini, pengguna dilibatkan dalam proses pengembangannya agar mendapat umpan balik dengan cepat. Dampaknya dapat meminimalkan kesalahan perancangan sistem dan komunikasi berlangsung dengan efektif dan efisien.

Sebelum merancang sistem, dilakukan analisis spesifikasi kebutuhan yang terdiri dari kebutuhan fungsional dan non fungsional. Di antara kebutuhan fungsional untuk sistem repositori ini adalah sebagai berikut:

1. Sistem dapat mengelola data dengan aksi menambahkan, menampilkan, mengubah, dan menghapus data.

2. Sistem menyediakan informasi:

a. Data profil yang terdiri dari nama, NIP, NIDN, email, alamat, foto;

b. Data pendidikan yang terdiri dari riwayat pendidikan, lampiran dokumen ijazah;

c. Data penelitian yang terdiri dari riwayat penelitian, lampiran dokumen surat tugas, jurnal, dan sertifikat;

d. Data kepangkatan yang terdiri dari riwayat kepangkatan dan lampiran dokumen terkait;

e. Data sertifikasi yang terdiri dari riwayat sertifikasi, lampiran dokumen surat tugas, dan sertifikat;

f. Data pelatihan yang terdiri dari riwayat pelatihan, lampiran dokumen surat tugas, dan sertifikat;

g. Data pengajaran yang terdiri dari riwayat mengajar mata kuliah dan prodi serta lampiran dokumen pendukungnya;

h. Data pengabdian yang terdiri dari riwayat pengabdian kepada masyarakat, lampiran dokumen surat tugas dan laporan.

3. Sistem dapat melakukan unggah dokumen penunjang.

4. Sistem dapat melakukan pencarian data yang relevan sesuai kata kunci.

Untuk kebutuhan non-fungsional, sistem harus dapat diakses oleh akun yang telah terdaftar. Sistem memiliki dua hak akses, yaitu admin dan dosen. Selain itu, diharapkan memiliki tampilan yang user friendly dan dapat diakses dari berbagai perangkat. 
Agar dapat melihat perbedaan proses bisnis yang dilakukan sebelumnya dan setelah ada sistem ini, maka dibuat dua buah proses bisnis.

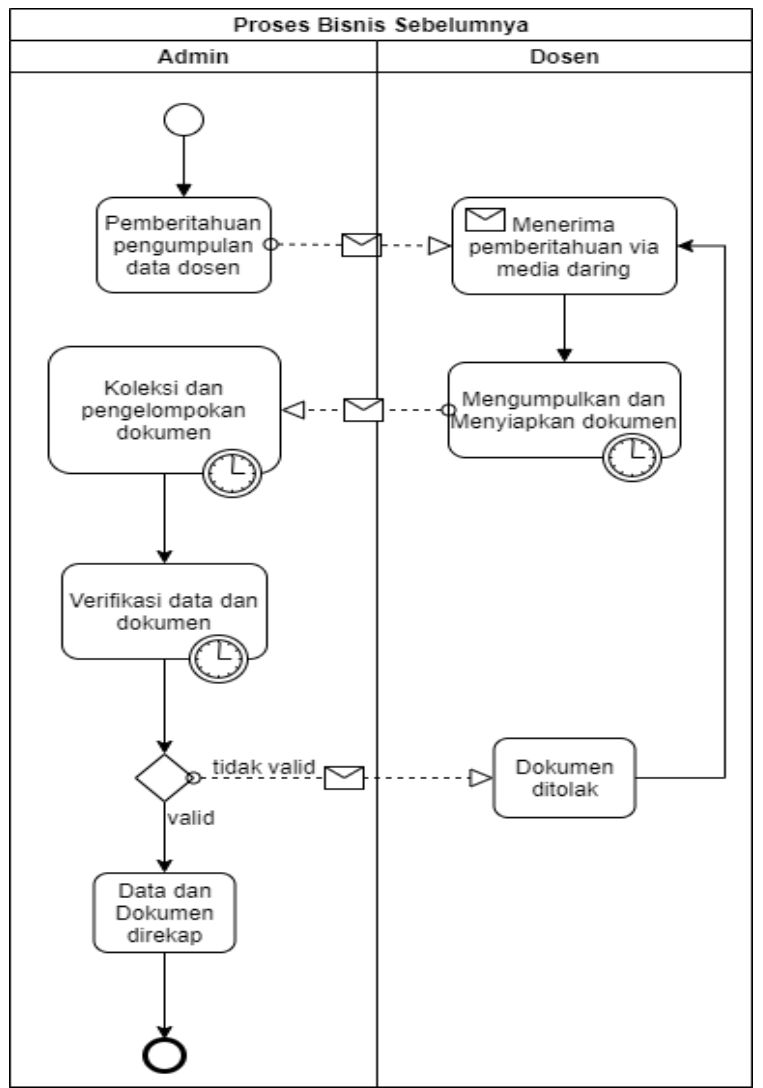

Gambar 1. Proses bisnis sebelumnya

Pada gambar 1 menunjukkan proses bisnis sebelum sistem ini dibuat, Pada gambar 2 adalah proses bisnis usulan untuk sistem ini.

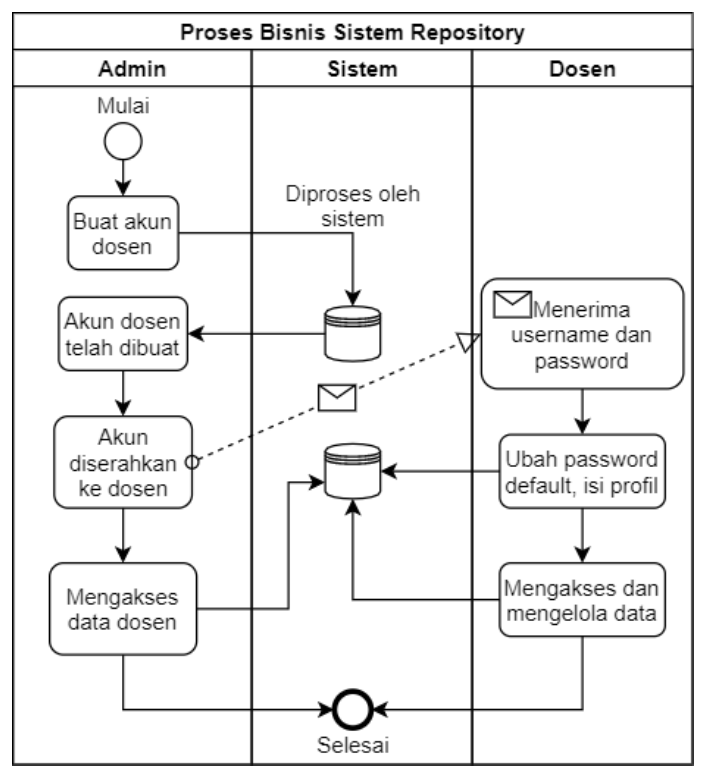

Gambar 2. Proses bisnis usulan 
Kemudian dilakukan perancangan sistem menggunakan bahasa pemodelan atau Unified Modeling Language (UML) [13]. Berikut ini bagian use case diagram (gambar 3), rancangan basis data (gambar 4), dan class diagram (gambar 5) dari sistem yang akan dibangun.

1) Use Case Diagram

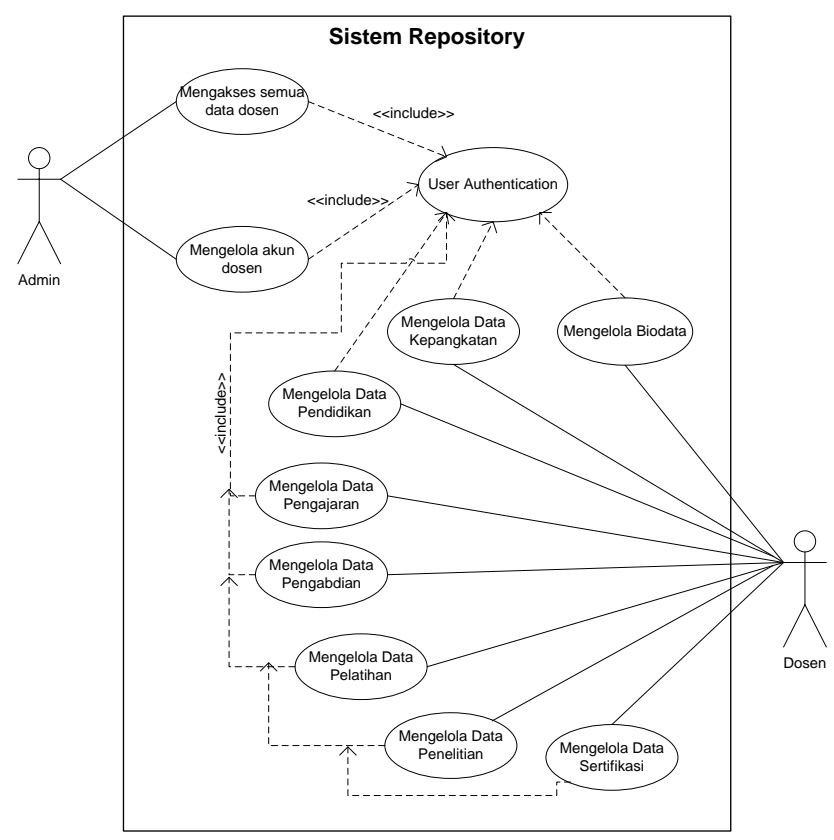

Gambar 3. Use case diagram sistem repositori

2) Rancangan Basis Data

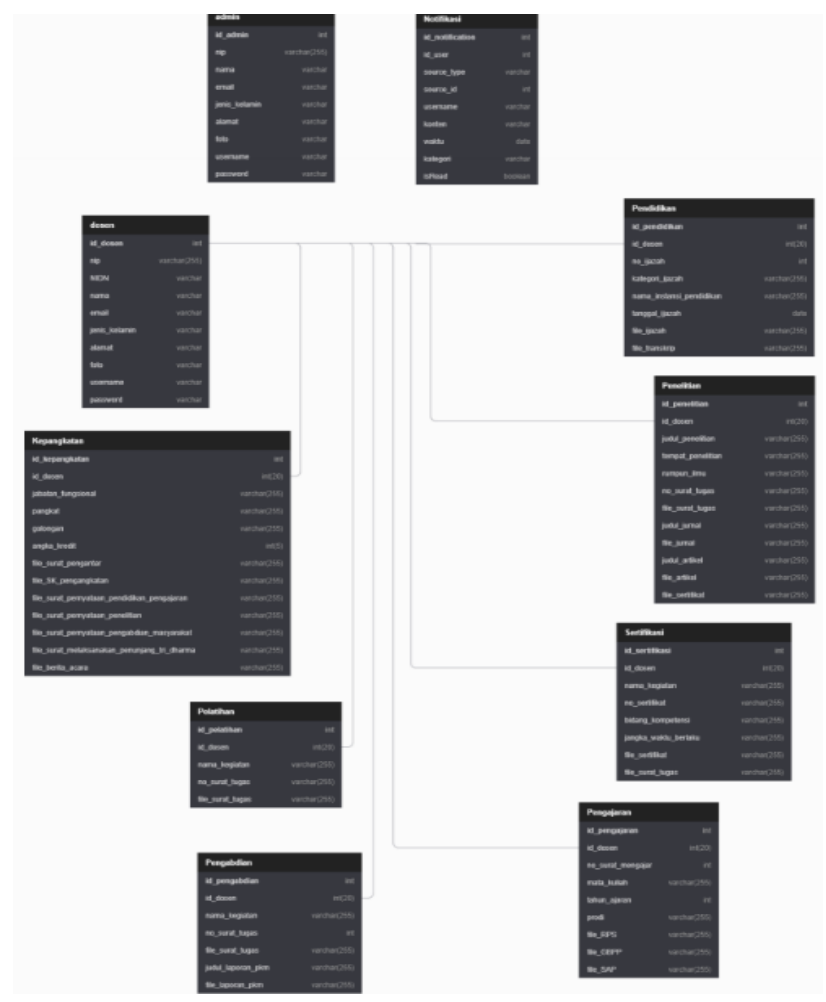

Gambar 4. Rancangan basis data 


\section{3) Class Diagram}

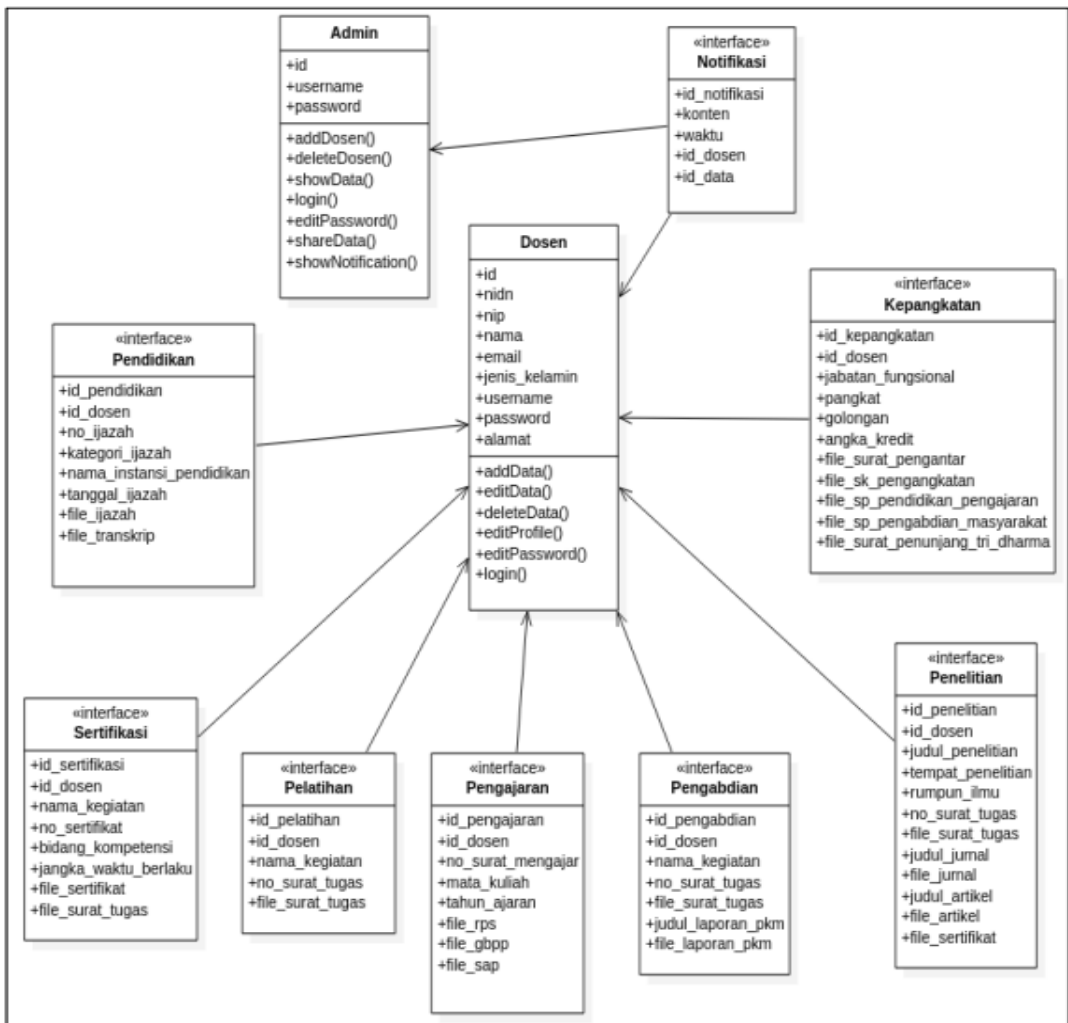

Gambar 5. Class diagram

\subsection{Implementasi Sistem}

Sistem dibuat menggunakan framework React. Terdapat dua versi aplikasi yang dibangun, yaitu versi web dan Android (.apk). Ilustrasi arsitektur sistem dapat dilihat pada gambar 6 berikut ini.

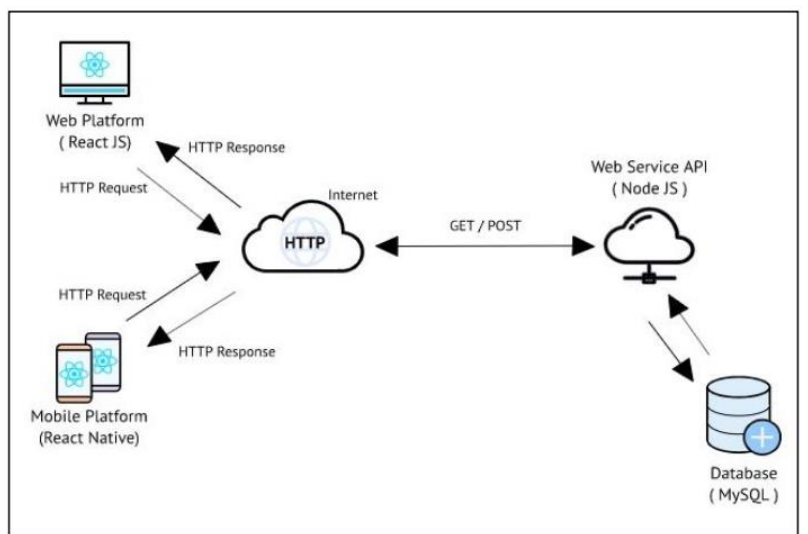

Gambar 6. Arsitektur sistem multiplatform berbasis React

Dari gambar 6 terdapat beberapa bagian penting, yaitu:

1. Basis data MySQL, untuk menyimpan data.

2. Web service API dengan NodeJS, untuk antarmuka pertukaran data multiplatform dari aplikasi versi Android dan web.

3. React JS (library) [3], untuk membangun antarmuka versi web.

4. React Native (framework) [6], untuk membangun aplikasi versi Android. 


\title{
2.5. Pengujian Sistem
}

Sebelum diserahkan kepada pengguna, dilakukan pengujian sistem. Minimal kebutuhan fungsional dapat dipastikan telah berjalan dengan baik dan benar. Pengujian fungsional [14] dilakukan berdasarkan daftar kebutuhan fungsional (functional requirements) yang telah dirancang sebelumnya. Secara garis besar, pengujian terbagi menjadi dua bagian, yaitu pengujian fungsional dengan positif tes dan negatif tes. Positif tes dimaksudkan untuk memastikan respon sistem sesuai dengan harapan terhadap data yang diinput adalah data yang valid, sedangkan negatif tes bertujuan untuk menguji respon sistem terhadap data yang tidak valid. Secara umum skenario pengujian yang telah dilakukan dapat dilihat pada tabel 1 berikut ini.

Tabel 1. Skenario pengujian fungsional sistem

\begin{tabular}{|c|c|c|}
\hline No. & $\begin{array}{l}\text { Jenis } \\
\text { Akun }\end{array}$ & Daftar Fungsional \\
\hline 1 & $\begin{array}{l}\text { Admin, } \\
\text { Dosen }\end{array}$ & Form login \\
\hline 2 & Admin & $\begin{array}{l}\text { Kelola akun: } \\
\text { a. Membuat akun } \\
\text { b. Mengedit akun } \\
\text { c. Menghapus akun } \\
\text { d. Melihat daftar } \\
\text { akun } \\
\text { e. Verifikasi akun }\end{array}$ \\
\hline 3 & Admin & $\begin{array}{l}\text { Kelola data } \\
\text { dokumen digital } \\
\text { semua akun dosen } \\
\text { a. Menambah data } \\
\text { b. Mengedit data } \\
\text { c. Menghapus data } \\
\text { d. Melihat rincian } \\
\text { data }\end{array}$ \\
\hline
\end{tabular}

4 Admin, Notifikasi Dosen

5 Admin, Logout Dosen

6 Dosen Form register

\author{
Form diis \\ data valid
} Positif Tes

Menggunak an akun yang valid

Form diisi
data valid

Skena




\begin{tabular}{|c|c|c|c|c|c|c|}
\hline \multirow[t]{2}{*}{ No. } & \multirow{2}{*}{$\begin{array}{l}\text { Jenis } \\
\text { Akun }\end{array}$} & \multirow{2}{*}{ Daftar Fungsional } & \multicolumn{2}{|c|}{ Skenario Pengujian } & \multirow[t]{2}{*}{$\begin{array}{l}\text { Hasil yang } \\
\text { diharapkan }\end{array}$} & \multirow[t]{2}{*}{$\begin{array}{c}\text { Hasil } \\
\text { Pengujian } \\
\end{array}$} \\
\hline & & & Positif Tes & Negatif Tes & & \\
\hline 7 & Dosen & $\begin{array}{l}\text { Kelola data / } \\
\text { dokumen digital } \\
\text { a. Menambah data } \\
\text { b. Mengedit data } \\
\text { c. Menghapus data } \\
\text { d. Melihat rincian } \\
\text { data }\end{array}$ & $\begin{array}{l}\text { Form diisi } \\
\text { data valid }\end{array}$ & $\begin{array}{l}\text { Form kosong semua } \\
\text { atau sebagian, isi data } \\
\text { yang sama, data tidak } \\
\text { valid seperti nama } \\
\text { dokumen dengan } \\
\text { angka, unggah } \\
\text { dokumen selain } \\
\text { PDF/gambar scan. }\end{array}$ & $\begin{array}{l}\text { Positif: } \\
\text { Data terekam. } \\
\text { Negatif: respon } \\
\text { ditolak. }\end{array}$ & Sukses \\
\hline
\end{tabular}

Pengujian fungsional sistem juga dilakukan pada perangkat yang berbeda-beda. Terutama untuk fitur notifikasi yang dilakukan pada dua perangkat dengan masuk sebagai akun admin dan dosen. Sehingga ketika pengguna melakukan aksi perubahan atau pembaruan data, admin atau dosen akan mendapatkan notifikasi. Pada tabel 2 pengujian fungsional untuk aplikasi versi web dilakukan pada perangkat laptop dan tabel 3 pengujian fungsional untuk aplikasi versi Android dilakukan pada perangkat gawai.

Tabel 2. Pengujian fungsional sistem versi web

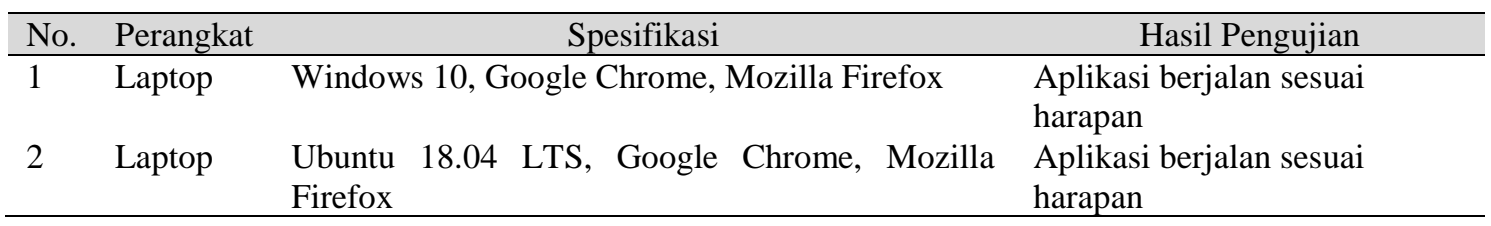

Tabel 3. Pengujian fungsional sistem versi Android

\begin{tabular}{llll}
\hline No. & \multicolumn{1}{c}{ Perangkat } & \multicolumn{1}{c}{ Spesifikasi } & Hasil Pengujian \\
\hline 1 & Xiaomi Redmi 5A & Android 7.0 RAM 2GB & Aplikasi berjalan sesuai harapan \\
2 & Xiaomi Redmi 4A & Android 6.0 RAM 2GB & Aplikasi berjalan sesuai harapan \\
3 & Xiaomi Redmi 5 Plus & Android 6.0 RAM 2GB & Aplikasi berjalan sesuai harapan \\
\hline
\end{tabular}

\section{HASIL DAN PEMBAHASAN}

Sistem yang telah dirancang dan dibangun terdiri dari aplikasi versi web dan Android. Berikut ini tampilan antarmuka pengguna yang telah dibangun.

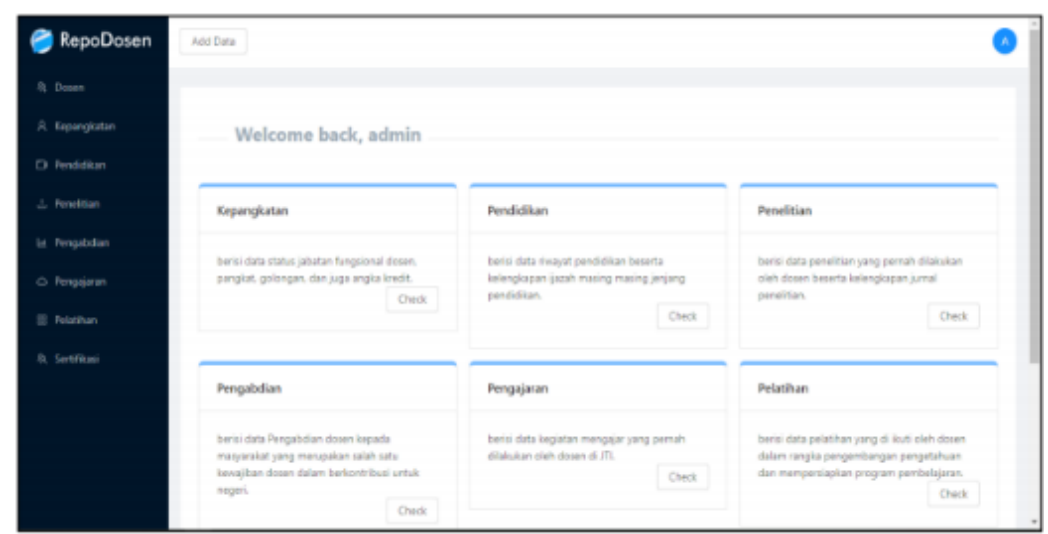

Gambar 7. Tampilan halaman beranda admin 
3.1 Tampilan antarmuka pengguna versi web

Berikut ini merupakan hasil tampilan versi web.

a) Beranda Admin login.

Pada gambar 7 merupakan halaman beranda Admin yang hanya dapat diakses setelah

b) Beranda Dosen

Pada gambar 8 merupakan halaman beranda dosen yang hanya dapat diakses setelah mendapat akun dari admin. Pada halaman beranda ini terdapat ringkasan konten pada tiap kategori data atau dokumen.

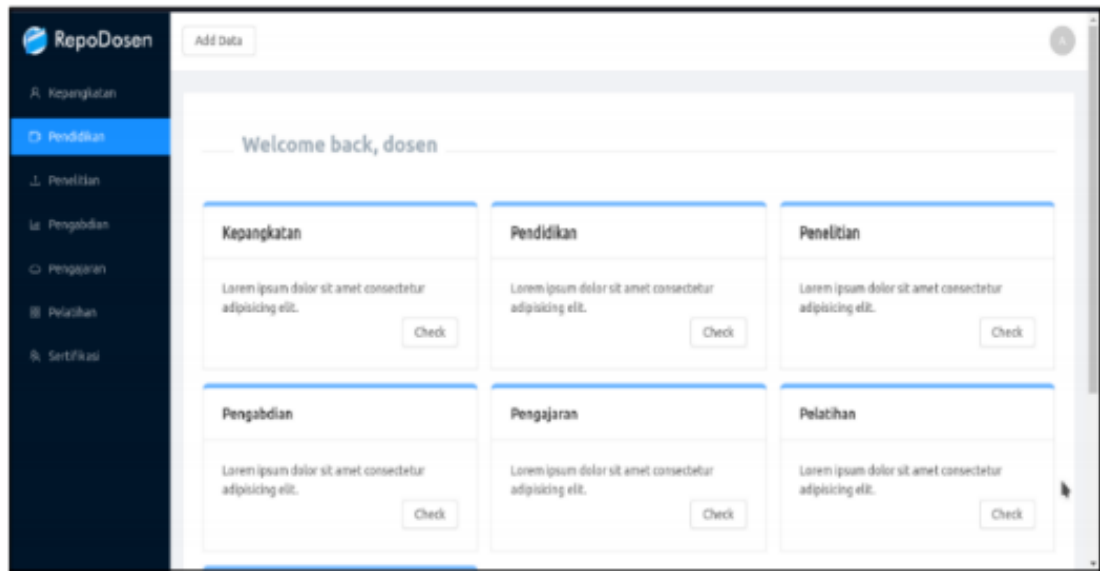

Gambar 8. Tampilan halaman beranda dosen

c) Konfigurasi Profil

Pada gambar 9 merupakan halaman untuk mengatur data diri atau biodata dari akun.

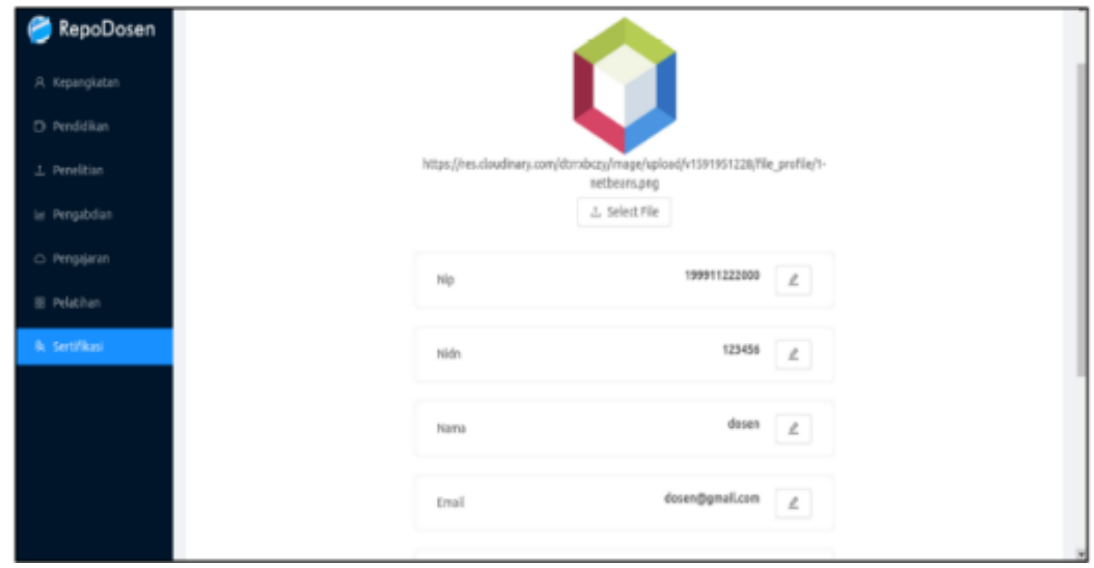

Gambar 9. Tampilan halaman konfigurasi profil

d) Admin: Tambah Akun Dosen

Pada gambar 10 merupakan halaman untuk menambah akun dosen yang hanya dapat dilakukan oleh admin. 


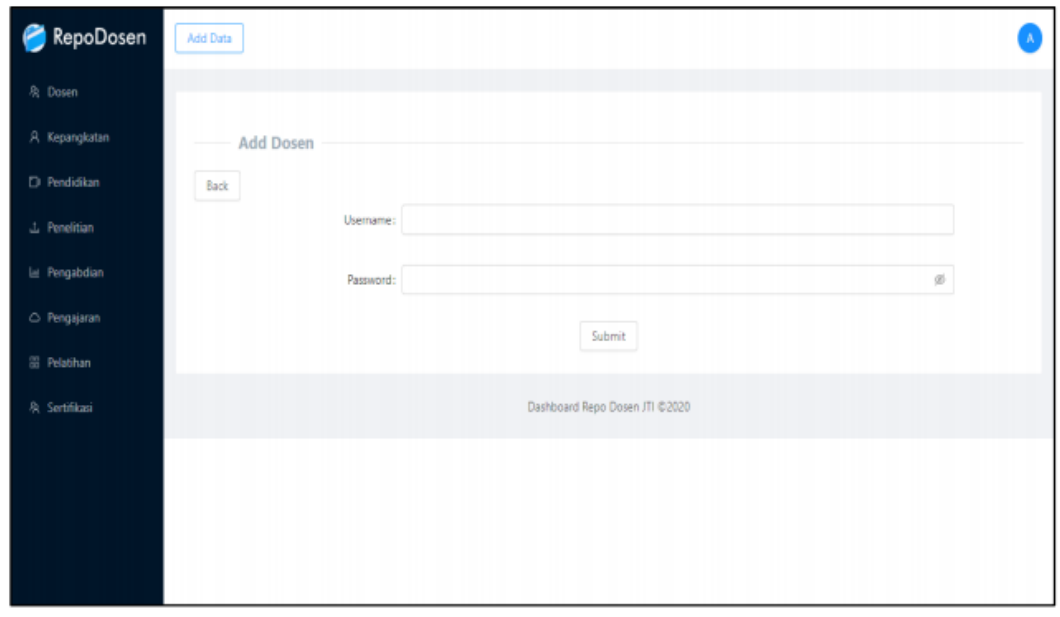

Gambar 10. Tampilan halaman tambah akun

e) Admin: Verifikasi Akun Dosen

Pada gambar 11 merupakan halaman yang hanya dapat diakses oleh admin untuk mengaktifkan atau memverifikasi akun dosen yang telah dibuat.

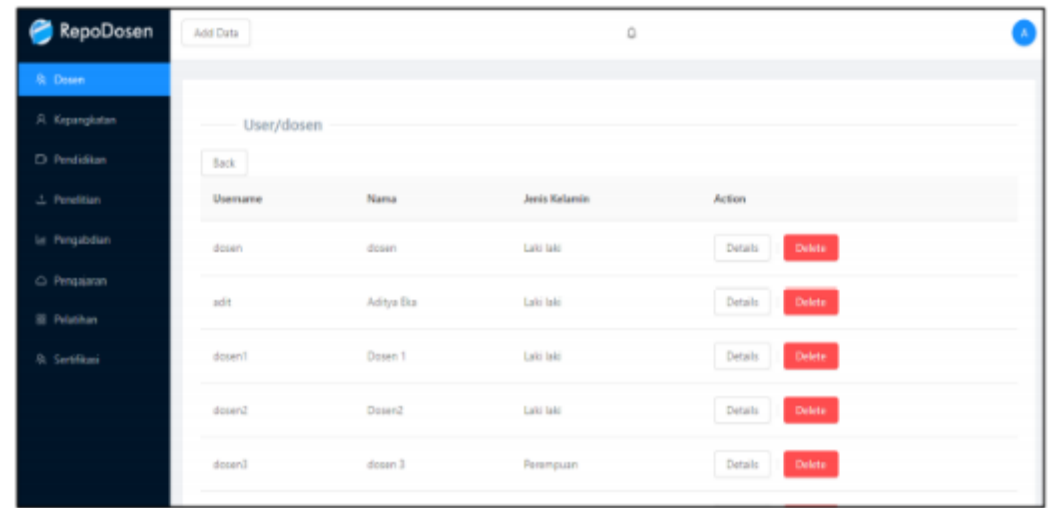

Gambar 11. Tampilan halaman verifikasi akun

f) Registrasi Akun Dosen

Pada gambar 12 berikut merupakan tampilan halaman untuk mendaftar akun dosen. Kemudian diaktivasi oleh admin, selanjutnya baru bisa login dan mulai mengisi atau mengunggah data dosen.

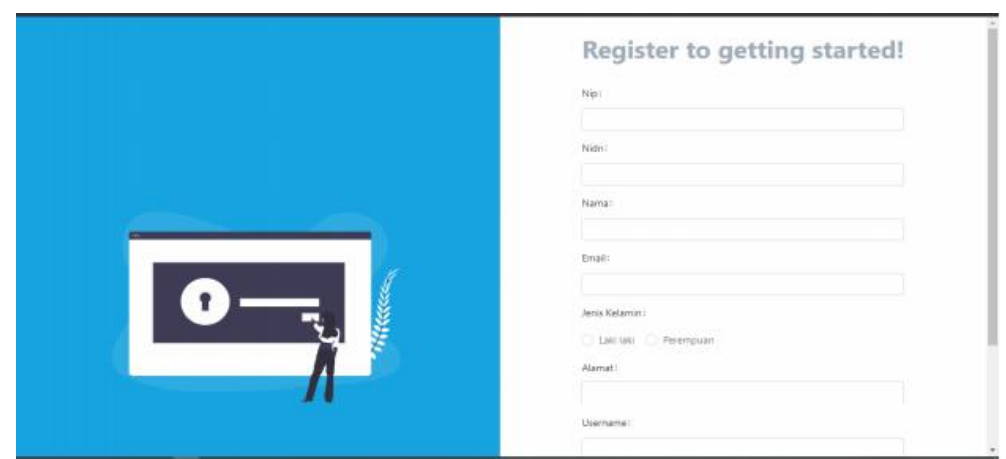

Gambar 12. Tampilan halaman registrasi dosen

g) Admin: Tambah Dokumen Dosen 
Pada gambar 13 merupakan tampilan halaman untuk menambah data atau dokumen yang dilakukan oleh admin jika sewaktu-waktu dosen kesulitan untuk mengunggahnya.

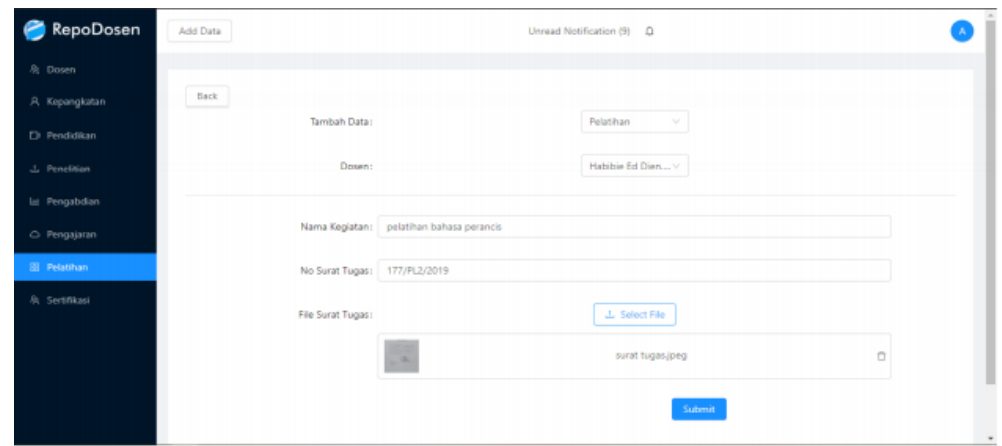

Gambar 13. Tampilan halaman tambah data

h) Tambah Data atau Dokumen

Pada gambar 14 merupakan tampilan halaman untuk menambah data atau dokumen yang dilakukan oleh dosen.

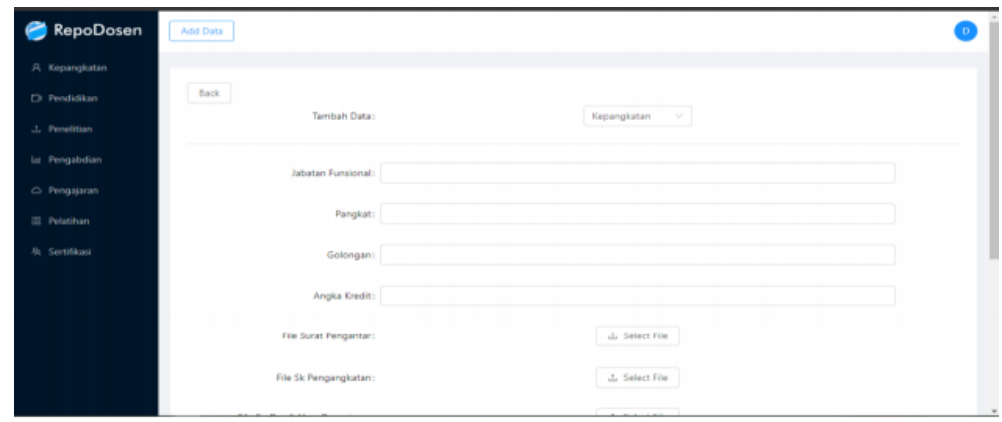

Gambar 14. Tampilan halaman tambah data

i) Ubah Data atau Dokumen

Pada gambar 15 merupakan tampilan halaman untuk megubah data atau dokumen jika ada kesalahan atau perbaikan.

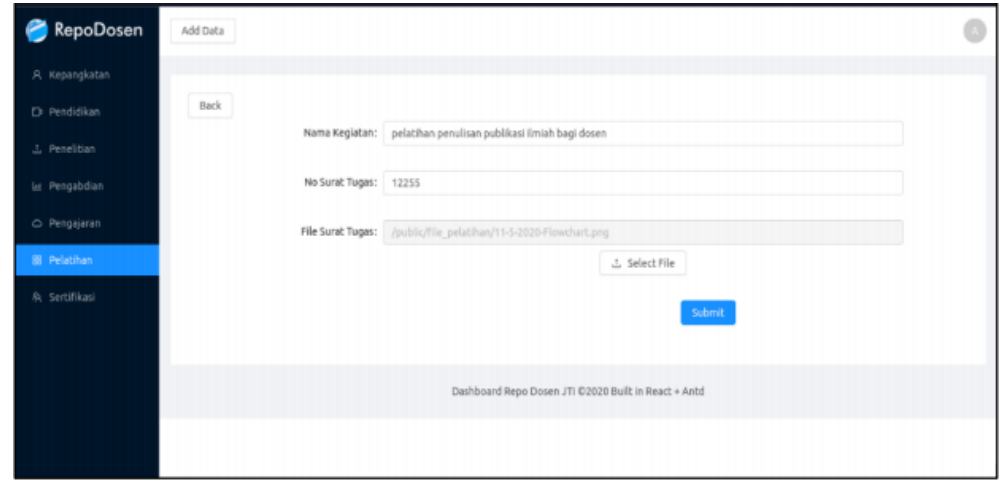

Gambar 15. Tampilan halaman ubah data

j) Notifikasi

Pada gambar 16 mengilustrasikan pemberitahuan yang diterima oleh admin atau dosen jika ada aksi atau pengumuman penting maupun berkas yang berhasil diunggah. 


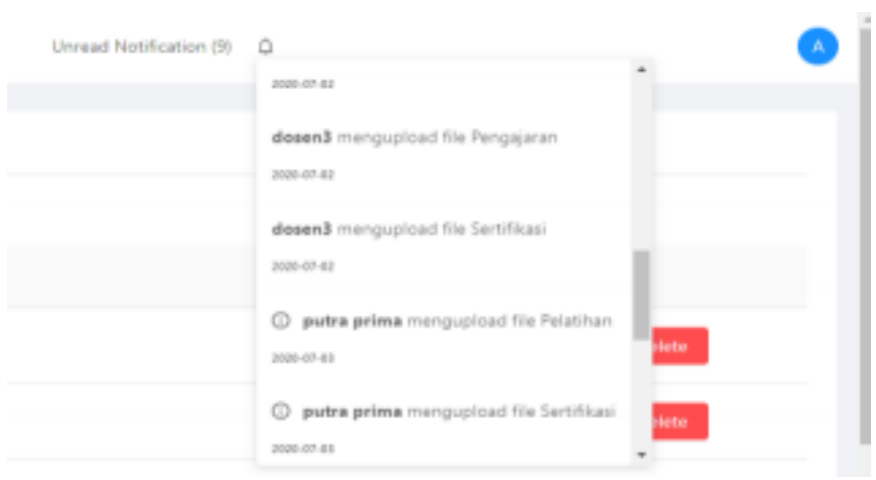

Gambar 16. Tampilan notifikasi

k) Lihat Rincian Dokumen

Pada gambar 17 merupakan tampilan halaman untuk melihat rincian data atau dokumen yang telah berhasil diunggah atau diperbarui.

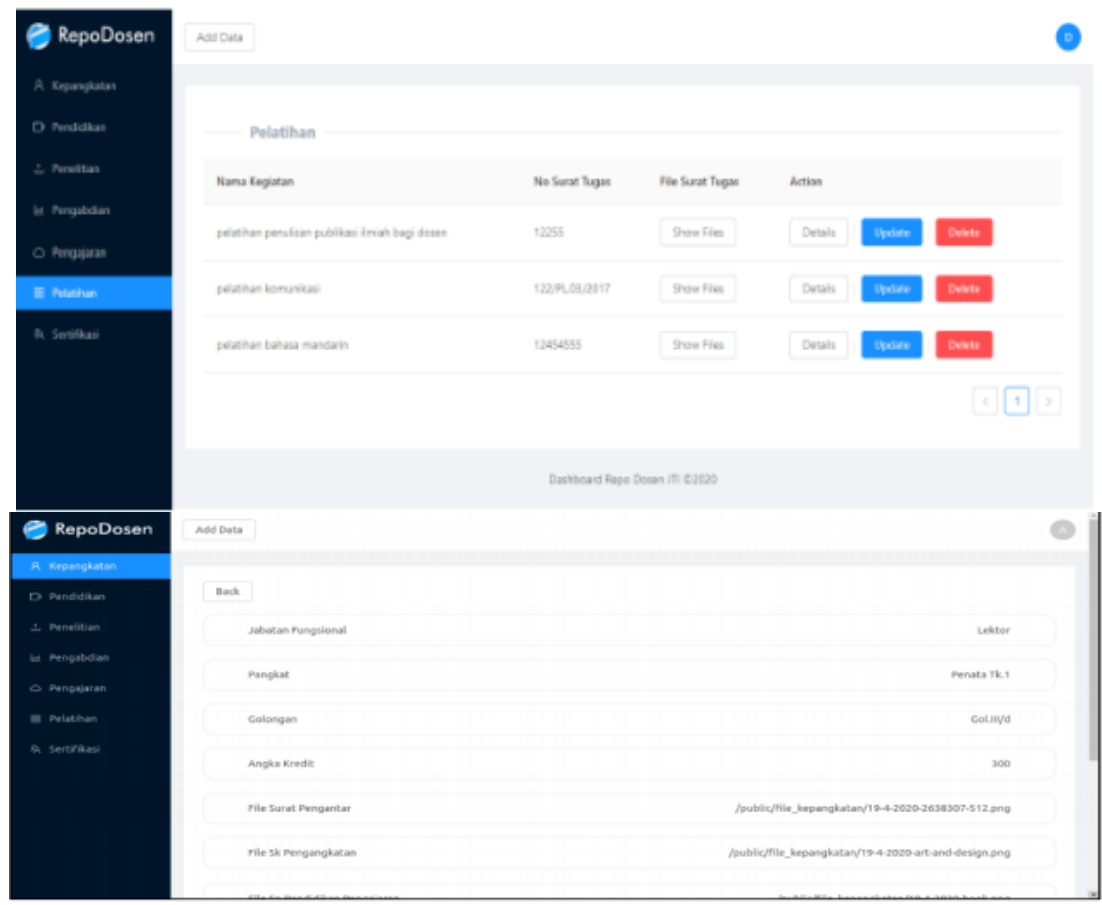

Gambar 17. Tampilan halaman rincian data

3.2 Tampilan antarmuka pengguna versi Android

Berikut ini merupakan hasil tampilan versi Android.

a) Login dan Beranda

Pada gambar 18 (a) merupakan tampilan untuk login admin maupun dosen pada aplikasi Android, sedangkan gambar 18 (b) merupakan tampilan halaman beranda untuk admin dan dosen. 


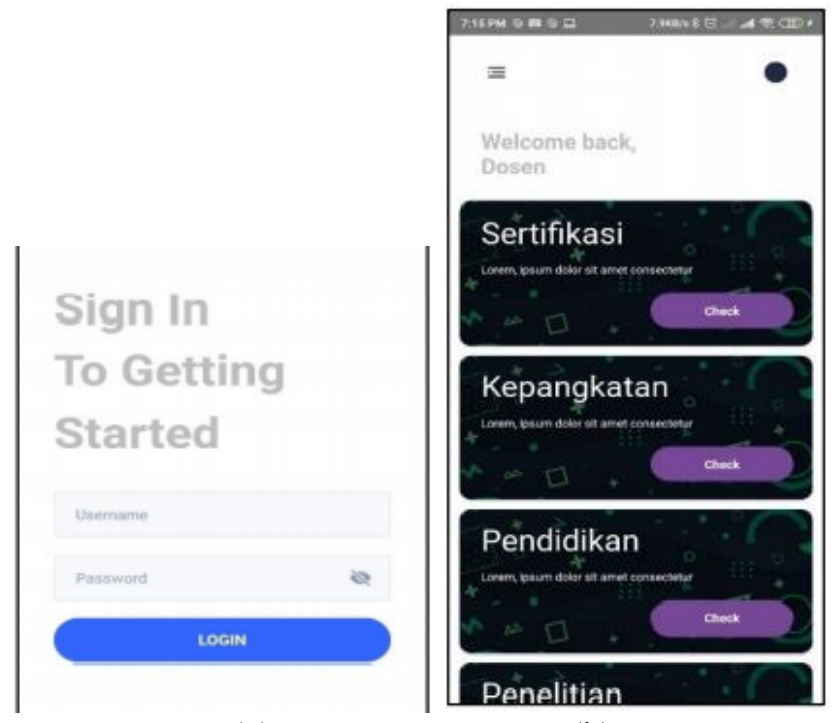

(a)

(b)

Gambar 18. (a) Tampilan halaman login; (b) Tampilan halaman beranda

b) Konfigurasi Profil

Pada gambar 20 merupakan tampilan halaman untuk melengkapi biodata atau profil baik untuk admin maupun dosen.

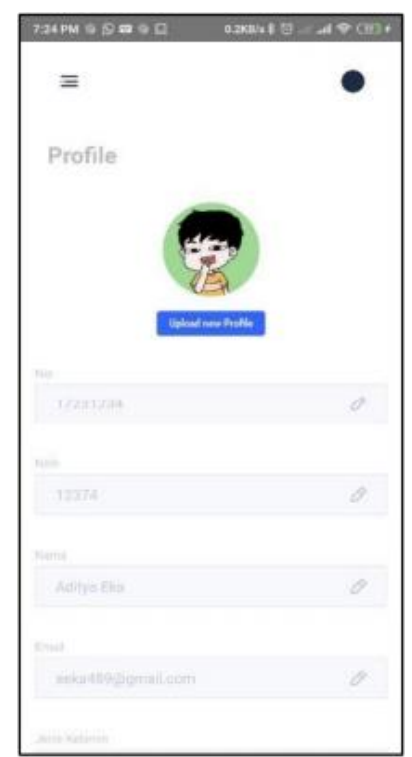

Gambar 20. Tampilan halaman profil

c) Lihat Rincian Dokumen

Pada gambar 21 merupakan tampilan pada aplikasi Android untuk melihat rincian data atau dokumen yang telah berhasil diunggah.

d) Tambah Data atau Dokumen

Pada gambar 22 (a) merupakan tampilan halaman untuk menambahkan data atau dokumen, sedangkan gambar 22 (b) merupakan tampilan halaman untuk mengubah data atau dokumen jika ada yang perlu direvisi. 


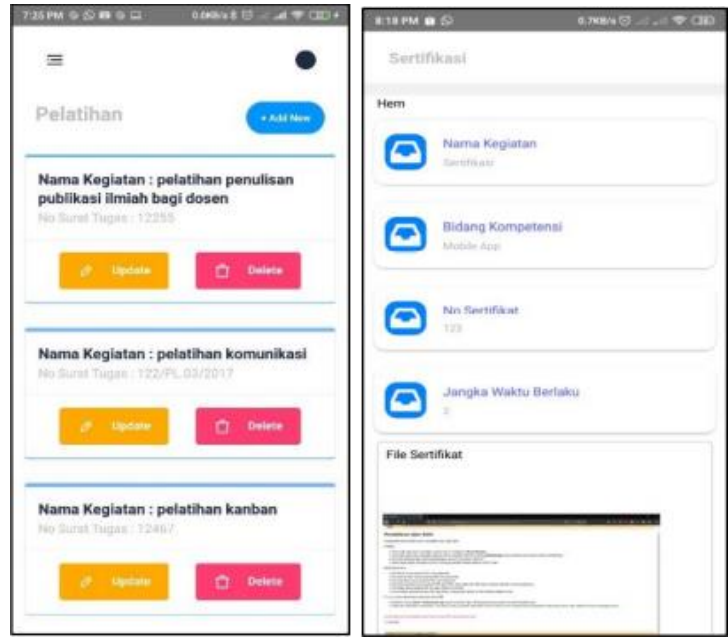

Gambar 21. Tampilan halaman rincian data

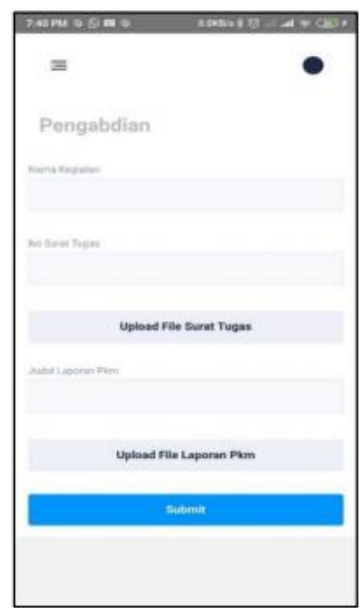

(a)

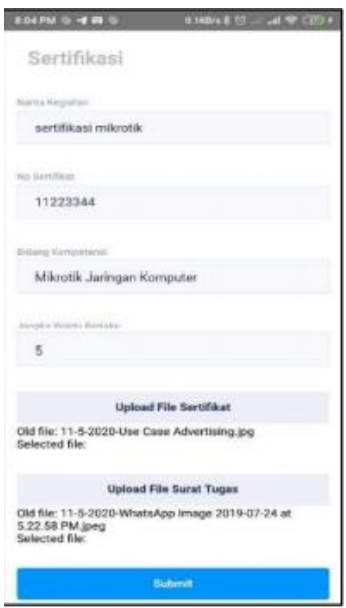

(b)

Gambar 22. (a) Tampilan halaman tambah data; (b) Tampilan halaman ubah data

\section{KESIMPULAN}

Berdasarkan penelitian yang telah dilakukan, terdapat beberapa poin penting yang dapat disimpulkan antara lain sistem multiplatform yang dikembangkan dapat diakses dari berbagai perangkat seperti komputer meja, gawai, tablet. JavaScript merupakan bahasa pemrograman yang dapat beroperasi di berbagai platform. ReactJS digunakan untuk versi web dan React Native beroperasi pada gawai Android yang menghasilkan Android Package (APK) yang mendukung notifikasi untuk user. React merupakan library JavaScript untuk antarmuka yang dapat dengan cepat membantu pengembangan perangkat lunak multiplatform versi web dan Android. Web service API menjadi jembatan komunikasi antar platform, sehingga dapat dikembangkan lebih lanjut untuk integrasi dengan platform lainnya. Fitur notifikasi sangat bermanfaat untuk memberikan informasi terkini dengan cepat. Sistem dapat menyimpan data-data dosen dengan baik dan terstruktur di basis data. Sistem ini merupakan pengembangan dari sistem repositori Beban Kerja Dosen (BKD) yang dapat dimanfaatkan untuk mengolah data tridharma perguruan tinggi. Framework Kanban dapat mempercepat proses pengembangan perangkat lunak sesuai yang diharapkan oleh pengguna. 


\section{SARAN}

Penelitian ini dapat dilanjutkan dengan ide-ide yang lebih kreatif, efektif, dan efisien untuk menunjang pekerjaan admin maupun dosen menjadi lebih baik. Beberapa fitur yang dapat dikembangkan lebih lanjut, seperti mendeteksi nomor surat tugas dokumen secara otomatis sehingga dapat dilakukan temu kembali informasi dan rekam jejak yang mudah untuk dianalisis. Kemudian pada bagian halaman utama dapat ditambahkan grafik kualifikasi dosen, jumlah, rasio, dan sebagainya, sehingga sangat berguna untuk para pemangku kepentingan dalam mengambil kebijakan. Isu lain yang dapat dikembangkan lebih lanjut adalah pengolahan dokumen digital dengan teknologi data warehouse yang memungkinkan untuk disimpan dan analisis dengan dukungan teknologi awan.

\section{DAFTAR PUSTAKA}

[1] Kemdikbud, "Kamus Besar Bahasa Indonesia: Repositori," 2020. https://kbbi.kemdikbud.go.id/entri/repositori.

[2] "Peraturan BAN-PT Nomor 3 Tahun 2019." https://www.banpt.or.id/wpcontent/uploads/2019/09/Lampiran-02-PerBAN-PT-3-2019-Kriteria-dan-Prosedur-IAPT3_0.pdf (accessed May 06, 2021).

[3] Facebook, "React - A JavaScript library for building user interfaces," 2020. https://reactjs.org/.

[4] "The State of JavaScript 2019: Front End Frameworks." https://2019.stateofjs.com/frontend-frameworks/ (accessed Mar. 25, 2021).

[5] “13 Best JavaScript Frameworks For 2020.” https://www.lambdatest.com/blog/bestjavascript-framework-2020/ (accessed Mar. 25, 2021).

[6] Facebook, "React Native · A framework for building native apps using React," 2020. https://reactnative.dev/.

[7] F. Nugraha, W. Triyanto, M. Arifin, and Y. Rahayu, "Rancang Bangun Sistem Informasi Penilaian Beban Kerja Dosen," Simetris J. Tek. Mesin, Elektro dan Ilmu Komput., pp. 405412,2019,[Online].Available: https://jurnal.umk.ac.id/index.php/simet/article/view/3312.

[8] D. Vitalocca, S. E. Rahman, and P. A. Uleng, "Perancangan Sistem Informasi Data Dosen Jurusan Pendidikan Teknik Elektro Universitas Negeri Makassar Berbasis Web," $J$. MEKOM (Media Komun. Pendidik. Kejuruan), vol. 5, no. 1, 2018, [Online]. Available: https://ojs.unm.ac.id/mkpk/article/view/8222.

[9] A. Widarma and M. Rahmawan, "Rancang Bangun Sistem Informasi Rekam Jejak Dosen Berbasis WEB (Studi Kasus : Fakultas Teknik Universitas Asahan)," Jurti (Jurnal Teknol. Informasi),vol.2,no.1,2018,[Online].Available: http://jurnal.una.ac.id/index.php/jurti/article/view/406.

[10] N. Saraswati and E. Hartono, "Sistem Pengolahan Data Dosen Tetap STMIK STIKOM Indonesia Berbasis Website," Jutik (Jurnal Teknol. Inf. dan Komputer), vol. 3, no. 1, 2017.

[11] C. Tonyjanto, D. Marlita Martana, P. Studi Perekam dan Informasi Kesehatan, F. Ilmu Kesehatan Sains Dan Teknologi, and U. Dhyana Pura, "Perancangan Sistem Informasi Rekam Jejak Dosen Berbasis Web Pada Universitas Dhyana Pura Program Studi Sistem Informasi 1)," Oct. 2017. Accessed: May 09, 2021. [Online]. Available: http://repository.usu.ac.id/bitstream/12345678.

[12] Agile Allience, "The Agile Alliance website: Framework Kanban," 2020. https://www.agilealliance.org/glossary/kanban.

[13] "About the Unified Modeling Language Specification Version 2.5.1." https://www.omg.org/spec/UML (accessed Mar. 24, 2021).

[14] S. Zalavadia, "Functional Testing: A Complete Guide with Types and Example." https://www.softwaretestinghelp.com/guide-to-functional-testing/ (accessed May 01, 2021). 